\title{
PENYULUHAN KESEHATAN MASYARAKAT: PENGETAHUAN MENGENAI BABS, PENGELOLAAN SAMPAH RUMAH TANGGA, DAN COVID-19
}

\author{
Abdul Wahid'), Sofia Raudhatul Muslimah2), Vina Mahyona ${ }^{3)}$, Lenie Marlinae ${ }^{4)}$ \\ 1)S1 Kesehatan Masyarakat Minat Administrasi dan Kebijakan Kesehatan, Fakultas Kedokteran, Universitas Lambung \\ Mangkurat, Banjarbaru, Kalimantan Selatan, Indonesia \\ 2)S1 Kesehatan Masyarakat Minat Keselamatan dan Kesehatan Kerja, Fakultas Kedokteran, Universitas Lambung \\ Mangkurat, Banjarbaru, Kalimantan Selatan, Indonesia \\ ${ }^{3}$ S1 Kesehatan Masyarakat Minat Kesehatan Lingkungan, Fakultas Kedokteran, Universitas Lambung Mangkurat, \\ Banjarbaru, Kalimantan Selatan, Indonesia \\ ${ }^{4)}$ Departemen Kesehatan Lingkungan, Fakultas Kedokteran, Universitas Lambung Mangkurat, Banjarbaru, Kalimantan \\ Selatan, Indonesia \\ Corresponding author: Abdul Wahid \\ E-mail : wahidabd561@gmail. com
}

\section{Diterima 25 Juni 2021, Direvisi 24 Juli 2021, Disetujui 25 Juli 2021}

\begin{abstract}
ABSTRAK
Kesehatan lingkungan merupakan aspek kesehatan masyarakat yang memperhatikan bentuk kehidupan dan kondisi sekeliling manusia yang menekankan pada pengawasan kesehatan terhadap berbagai faktor lingkungan. Untuk mewujudkan perilaku masyarakat yang higienis dan saniter secara mandiri dalam rangka meningkatkan derajat kesehatan masyarakat yang setinggi-tingginya maka dibuatlah program Sanitasi Total Berbasis Masyarakat (STBM). Tujuan diadakannya kegiatan ini adalah memberikan pendidikan kepada masyarakat tentang 2 pilar STBM, yaitu BABS dan sampah agar masyarakat mengetahui bahaya perilaku membuang air besar dan membuang sampah secara sembarangan. Metode kegiatan adalah penyampaian tidak langsung menggunakan perangkat dalam jaringan (daring) yaitu grup WhatsApp selama 9 hari. Hasil kegiatan diperoleh peningkatan pengetahuan masyarakat yaitu pengetahuan babs meningkat dari rata-rata 77 menjadi 97 , pengetahuan sampah meningkat dari rata-rata 71 menjadi 94 , pengetahuan covid-19 meningkat dari rata-rata 51 menjadi 83. Masyarakat desa disarankan sebaiknya lebih proaktif meningkatkan pengetahuan tentang kesehatan lingkungan melalui aktif dan hadir dalam penyuluhan mengenai BABS, pentingnya jamban sehat, pengelolaan sampah rumah tangga dan Covid-19 serta masalah-masalah kesehatan yang terjadi.
\end{abstract}

Kata kunci: pengetahuan; BABS; sampah; covid-19

\begin{abstract}
Environmental health is an aspect of public health that pays attention to the life form and conditions surrounding humans that emphasize health supervision of various environmental factors. To realize hygienic and sanitary community behavior independently to improve the highest level of public health, a Community-Based Total Sanitation (STBM) program was created. The purpose of this activity is to provide education to the community about the 2 pillars of STBM, namely open defecation and garbage so that the public knows the dangers of the behavior of throwing large water and littering indiscriminately. The method of activity is indirect delivery using online devices, namely WhatsApp groups for 9 days. The results of the activities obtained increased public knowledge, namely knowledge open defecation increased from an average of 77 to 97, garbage knowledge increased from an average of 71 to 94 , knowledge covid-19 increased from an average of 51 to 83 . Villagers are advised to be more proactive in improving knowledge about environmental health through being active and present in counseling on open defecation, the importance of healthy latrines, household waste management, and Covid-19 as well as health problems that occur.
\end{abstract}

Keywords: knowledge; defecate carelessly; waste; covid-19

\section{PENDAHULUAN}

Dipandang dari ilmu kesehatan, kesehatan lingkungan pada dasarnya adalah suatu kondisi atau keadaan lingkungan yang optimum sehingga berpengaruh positif terhadap terwujudnya status kesehatan yang optimum pula. Bahasan kesehatan lingkungan tersebut antara lain mencakup perumahan, penyediaan air bersih, pembuangan tinja dan 
sampah serta pembuangan air kotor (limbah), dan sebagainya (Pratomo, n.d.).

Peraturan Menteri Kesehatan Nomor 3 Tahun 2014 tentang Sanitasi Total Berbasis Masyarakat (STBM) menyatakan bahwa STBM adalah pendekatan untuk mengubah perilaku higienis dan saniter melalui pemberdayaan masyarakat dengan cara pemicuan. Adapun pilar STBM terdiri atas Perilaku Stop Buang Air Besar Sembarangan; Cuci Tangan Pakai Sabun; Pengelolaan Air Minum dan Makanan Rumah Tangga; Pengamanan Sampah Rumah Tangga; dan Pengamanan Limbah Cair Rumah Tangga. (Mukti et al., 2016).

Dua dari kelima pilar STBM yaitu perilaku stop BABS (Buang Air Besar Sembarang) dan pengamanan sampah rumah tangga, masih menjadi persoalan yang belum tertangani dengan baik di berbagai daerah-daerah, salah satunya di Desa Simpang Warga Kecamatan Aluh-aluh, Kabupaten Banjar, Provinsi Kalimantan Selatan. Desa Simpang Warga memiliki koordinat $27^{\circ}$ BB - $28^{\circ}$ BT serta $31^{\circ}$ LU - 33 LS. Seluas atau 4,00 km2 $400 \mathrm{Ha}$ dengan bentang wilayah dataran rendah dan terletak di daerah pantai atau pesisir. Rumah penduduk terbagi menjadi dua daerah, yaitu daerah daratan yang mempunyai jalan yang sudah beraspal dan daerah pesisir yang jalannya masih hanya berupa titian kayu.

Menurut Profil Kesehatan Indonesia tahun 2019 terdapat kesenjangan antara jumlah desa yang melaksanakan STBM dengan jumlah desa yang sudah stop BABS. Diketahui bahwa jumlah desa/kelurahan yang telah melaksanakan STBM berjumlah 57. 935 dari total 83. 441 desa/kelurahan, sedangkan jumlah desa stop BABS masih hanya berjumlah 23. 574 desa/kelurahan. Desa stop BABS di Kalimantan Selatan di tahun yang sama berjumlah 482 desa/kelurahan, jumlah ini masih begitu jauh dari total 2. 008 desa/kelurahan yang ada. Sedangkan kondisi pengamanan sampah menurut data Sistem Informasi Pengelolaan Sampah Nasional tahun 20172018, diketahui jumlah sampah Kabupaten Banjar Provinsi Kalimantan Selatan (Kalsel) yang di timbun di TPA sebanyak 113,90 ton/hari dan jumlah sampah yang tidak terkelola sebanyak 45,16 ton/hari (Kementerian Kesehatan RI, 2020).

Kehidupan masyarakat Kalimantan Selatan sejak dahulu dikenal sangat dejat dengan sungai, berbagai aktivitas kegiatan masyarakat sehari-hari memanfaatkan keberadaan sungai yang ada. Salah satu permasalahan atas kebiasaan ini yaitu masyarakat juga sering membuang air besar dan membuang sampah sembarangan di sungai sehingga perlu adanya perhatian serius tentang pengetahuan masyarakat (Rahman, 2014). Hidup berdampingan dengan sungai besar yang menjadi anak aliran dari laut, membuat masyarakat desa Simpang Warga RT. 05 bergantung pada sungai tersebut untuk mencukupi kebutuhan sehari-hari. Kurangnya kesadaran masyarakat dalam hal perilaku stop buang air besar sembarangan dan pengamanan sampah rumah tangga akan berakibat dalam hal partisipasi masyarakat dalam menjaga lingkungan sekitar dan mendukung upaya sanitasi total berbasis masyarakat. Oleh sebab itu perlu adanya suatu kegiatan yang berguna untuk menambah pengetahuan dan wawasan masyarakat mengenai BABS dan sampah agar terbentuk kesadaran untuk berperilaku stop buang air besar sembarangan dan mampu mengamankan sampah rumah tangga (Purnamasari I and Raharyani A, 2020).

Berdasarkan uraian di atas maka penting untuk diadakan pendidikan kepada masyarakat tentang BABS dan sampah agar masyarakat mengetahui bahaya perilaku membuang air besar dan membuang sampah secara sembarangan. Melalui pemberian pengetahuan, maka akan memunculkan pemahaman, lalu menjadi keyakinan, selanjutnya menjadi perilaku, kemudian menjadi kebiasaan di masyarakat. Perilaku stop BABS dan pengamanan sampah rumah tangga yang menjadi dua pilar dalam STBM dimaksudkan agar terwujud perilaku masyarakat yang higienis dan saniter secara mandiri dalam rangka meningkatkan derajat kesehatan masyarakat yang setinggi-tingginya.

\section{METODE}

Kegiatan pengabdian ini dilakukan oleh 3 orang mahasiswa Program Studi Kesehatan Masyarakat Universitas Lambung Mangkurat bersama dosen pendamping lapangan. Mahasiswa yang terlibat terdiri atas 2 orang perempuan dan 1 orang laki-laki. Sasaran pengabdian adalah warga RT. 05 Desa Simpang Warga, Kecamatan Aluh-Aluh, Kabupaten Banjar. Waktu pelaksanaan pengabdian dilakukan selama 2 bulan.

Pelaksanaan kegiatan pengabdian masyarakat untuk membiasakan hidup bersih dan sehat dalam hal penggunaan jamban sehat dan pengelolaan sampah rumah tangga, serta untuk mengetahui tentang Covid-19. Kegiatan dilakukan dari tanggal 07 Oktober 2020 - 30 November 2020. Dibuatnya grup Whatsapp ini untuk mempermudah kegiatan sosialisasi karena terbatas pandemi Covid-19 yang dimana tidak disarankan untuk turun lapangan langsung. 
Kegiatan dilakukan dengan pemberian soal pre-test melalui google form kepada peserta sebelum diberikan nya materi untuk mengetahui seberapa besar pengetahuan peserta tentang materi yang akan disampaikan oleh penyuluh. Dilanjutkan dengan inti acara, yaitu penyampaian materi oleh penyuluh dan dibagikan booklet, poster, leaflet dan video sebagai alat media dengan materi penggunaan jamban sehat, pengelolaan sampah rumah tangga dan Covid-19. Kemudian pemberian soal post-test melalui google form terkait materi yang telah disampaikan oleh penyuluh. Pengetahuan masyarakat yang didapatkan melalui penyuluhan dijadikan indikator tingkat pengetahuan masyarakat itu sendiri. Sehari setelah pemberian post-test, dilakukan pemeriksaan kuesioner evaluasi yang telah diisi oleh peserta penyuluhan. Setelah pemeriksaan kuesioner dilakukan, selanjutnya adalah crosscheck data, perekapan data, analisis data dan penyusunan laporan kegiatan PBL 2.

\section{HASIL DAN PEMBAHASAN}

Kegiatan Pengalaman Belajar Lapangan (PBL) II ini adalah lanjutan dari kegiatan pengumpulan data, dan Focus Group Discussion (FGD) PBL I yang dilaksanakan di Desa Simpang Warga Kecamatan Aluh-Aluh sebagaimana yang dapat dilihat pada gambar 1 berikut.

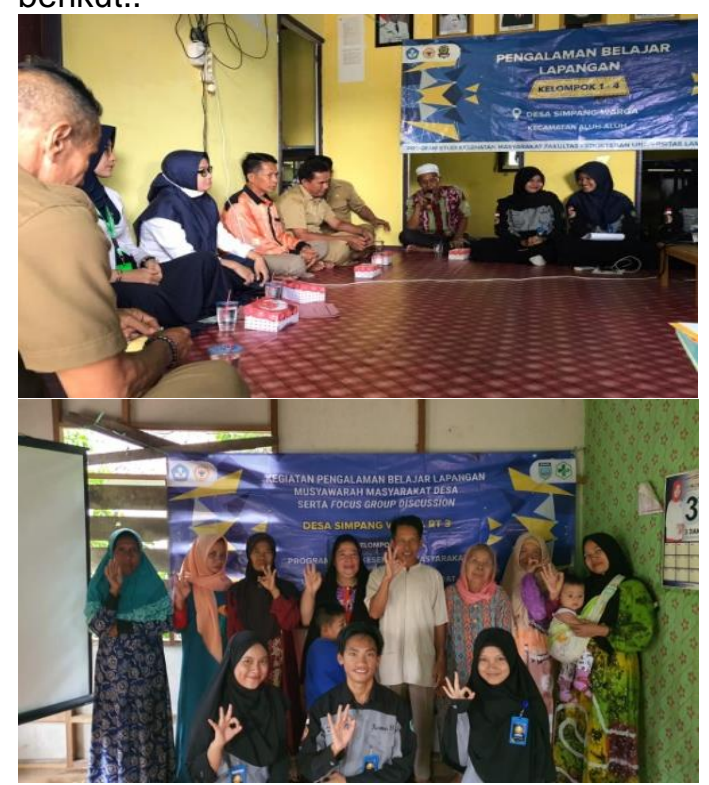

Gambar 1. Kegiatan Musyawarah dan FGD bersama warga pada PBL 1

Adapun warga yang mengikuti kegiatan lanjutan ini, yakni penyuluhan melalui platform Whatsapp dapat dilihat pada gambar 2, serta pengisian pre-post ialah berjumlah 7 orang. Diketahui bahwa nilai post-test sebagian besar responden meningkat dibandingkan dengan pre-test, hanya saja, ada 2 responden yang memiliki nilai tetap pada pre-post test Stop BABS dan pentingnya jamban sehat, 1 responden yang memiliki nilai pre-post test tetap pada materi pengelolaan sampah rumah tangga, dan 1 responden yang nilai pre-testnya lebih tinggi dibandingkan post-test.

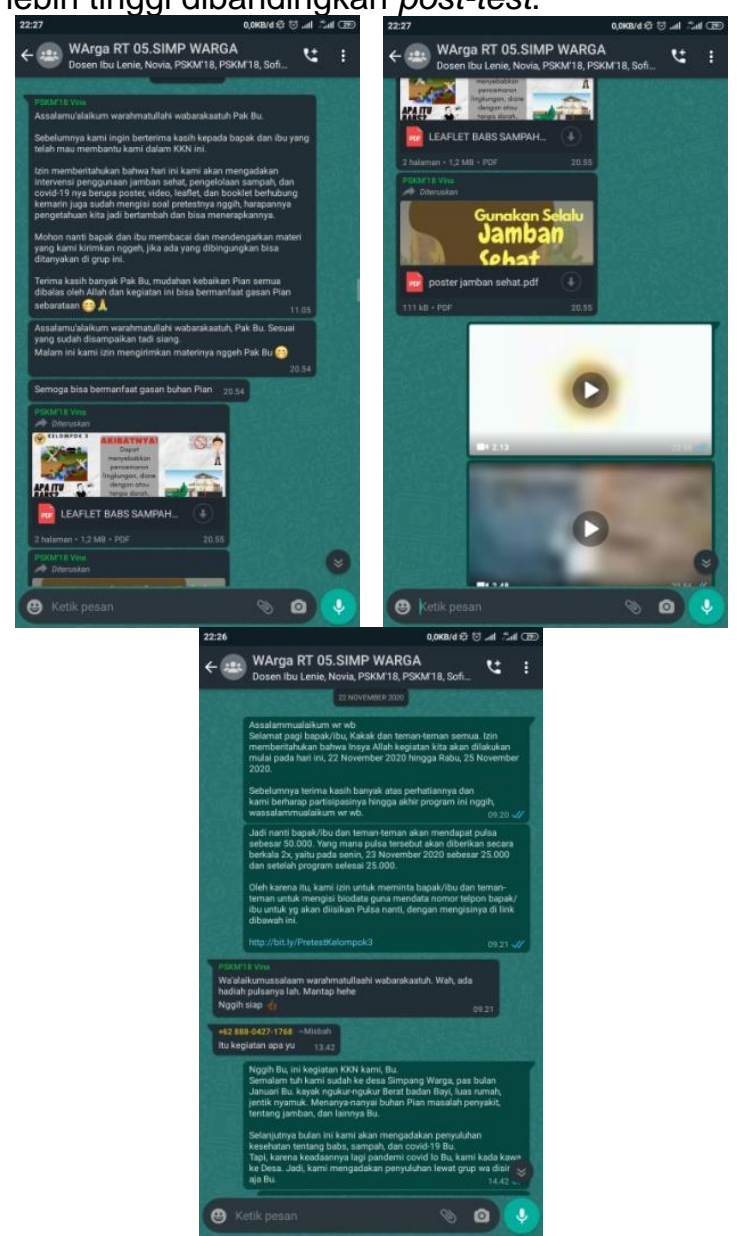

\section{Gambar 2. Penyuluhan Melalui Platform} Daring (WhatsApp)

Berikut adalah hasil kuesioner pre-test dan post-test yang diberikan kepada peserta kegiatan (responden) yaitu masyarakat Desa Simpang Warga Rt. 05 atas pemberian intervensi mengenai Stop Buang Air Besar Sembarangan (BABS) dan pentingnya penggunaan jamban sehat, pengelolaan sampah rumah tangga, dan adaptasi kebiasaan baru pandemi Covid-19.

Tabel 1. Hasil Distribusi Rata-Rata Pre dan Post Test Penyuluhan

\begin{tabular}{cccc}
\hline \multirow{2}{*}{ Materi } & Pre- & Post- & $\begin{array}{c}P \text { - } \\
\end{array}$ \\
& Test & Test & value \\
\hline
\end{tabular}

Stop BABS dan

Pentingnya

$\begin{array}{lll}77 & 97 & 0,38\end{array}$

Jamban Sehat

Pengelolaan

$\begin{array}{llll}\text { Sampah Rumah } & 71 & 94 & 0,24\end{array}$

Tangga 


\begin{tabular}{lccc}
\hline \multicolumn{1}{c}{ Materi } & $\begin{array}{c}\text { Pre- } \\
\text { Test }\end{array}$ & $\begin{array}{c}\text { Post- } \\
\text { Test }\end{array}$ & $\begin{array}{c}\boldsymbol{P} \text { - } \\
\text { value }\end{array}$ \\
\hline $\begin{array}{l}\text { Adabtasi } \\
\text { Kebiasaan Baru }\end{array}$ & & & \\
$\begin{array}{l}\text { Pandemi Covid- } \\
19\end{array}$ & 51 & 83 & 0,52 \\
\hline
\end{tabular}

\section{Pengetahuan Sebelum dan Sesudah Penyuluhan}

\section{Stop Buang Air Besar Sembarangan dan} Pentingnya Jamban Sehat

Pelaksanaan intervensi penyuluhan mengenai stop buang air besar sembarang dan pentingnya jamban sehat membuat pengetahuan masyarakat menjadi meningkat. Hal ini tergambar dari hasil rata-rata pre-post test selama kegiatan pada tabel 1.5 , terlihat dari nilai rata-rata ada saat pre test adalah sebesar 77 sedangkan nilai rata-rata pada saat post test adalah 97. Berdasarkan hasil penelitian Febriani dkk (2016), menyatakan bahwa pengetahuan seseorang akan berdampak pada tindakan seseorang atau perilaku seseorang. Seseorang dengan pengetahuan yang baik akan bertindak sesuai dengan apa yang ia ketahui, dan lebih cenderung akan memiliki perilaku yang lebih baik bila dibandingkan dengan seseorang dengan pengetahuan yang kurang baik, dalam hal ini adalah perilaku Stop BABS (Febriani et al., 2016).

Untuk dapat mengetahui perbedaan rata-rata antara sebelum dan sesudah intervensi penyuluhan maka dilakukan uji statistik. Hasil dari uji wilcoxon penyuluhan mengenai stop buang air besar sembarang dan pentingnya jamban sehat menunjukkan $p$-value sebesar 0.038 ( $p$-value<0. 05) yang artinya bahwa terdapat perbedaan rata-rata pengetahuan antara sebelum dan sesudah dilakukan penyuluhan. Salah satu faktor yang sangat penting dalam meningkatkan pengetahuan adalah dengan metode penyampaian informasi yang disesuaikan dengan kebutuhan sasaran dengan menggunakan media edukasi kesehatan yang tepat. Media edukasi kesehatan adalah semua sarana atau upaya untuk menampilkan pesan atau informasi yang ingin disampaikan oleh komunikator, baik itu melalui media cetak, elektronik (televisi, radio, komputer dan sebagainya) sehingga dapat meningkatkan pengetahuan dan merubah perilaku ibu terhadap kesehatan. Berdasarkan penelitian Renni Nur Fatmawati dalam Ramadhanti (2019) membuktikan bahwa pemberian penyuluhan memberikan pengaruh terhadap peningkatan pengetahuan dan sikap. Penyuluhan sebagai proses perubahan pengetahuan dan sikap yang menuntut persiapan dan pengetahuan yang memadai bagi penyuluh maupun sasarannya (Ramadhanti et al., 2019).

\section{Pengelolaan Sampah Rumah Tangga}

Penyuluhan mengenai pengelolaan sampah rumah tangga sudah dilaksanakan menjadikan peningkatan pengetahuan pada masyarakat. Dapat dilihat pada tabel 18 bahwa nilai rata-rata ada saat pre test adalah sebesar 71 , sedangkan nilai rata-rata pada saat post test adalah 94. Hal ini sejalan dengan penelitian Maghfiroh (2018) bahwa pengetahuan ibu rumah tangga tentang pengelolaan sampah meningkat setelah adanya penyuluhan. Peningkatan pengetahuan ini menunjukkan adanya pengaruh penyuluhan terhadap pengetahuan yang kemudian dianalisis secara statistik dengan menggunakan uji statistik (Maghfiroh et al., 2018).

Perbedaan rata-rata antara sebelum dan sesudah intervensi penyuluhan dapat diketahui dengan lakukan uji statistik. Hasil dari uji wilcoxon penyuluhan pengelolaan sampah rumah tangga ini menunjukkan $\mathrm{p}$-value sebesar 0.024 ( $p$-value<0. 05) yang artinya bahwa terdapat perbedaan rata-rata pengetahuan antara sebelum dan sesudah dilakukan penyuluhan. Salah satu strategi untuk memperoleh perubahan perilaku menurut $\mathrm{WHO}$ yang dikutip Maghfiroh dkk (2018) adalah dengan pemberian informasi untuk meningkatkan pengetahuan sehingga menimbulkan kesadaran dan pada akhirnya seseorang akan berperilaku sesuai dengan pengetahuannya tersebut. Salah satu upaya pemberian informasi yang dapat dilakukan adalah dengan penyuluhan. Penyuluhan memberi pengaruh yang bermakna (signifikan) terhadap perubahan pengetahuan ibu rumah tangga, khususnya pada pengelolaan sampah rumah tangga (Maghfiroh et al., 2018).

\section{Adaptasi Kebiasaan Baru Pandemi Covid-19}

Penyuluhan mengenai adaptasi kebiasaan baru pandemi covid-19 sudah dilaksanakan menjadikan peningkatan pengetahuan pada masyarakat. Dapat dilihat pada tabel 1. 11 bahwa nilai rata-rata ada saat pre test adalah sebesar 51, sedangkan nilai rata-rata pada saat post test adalah 83 . Terdapat satu orang yang mengalami penurunan nilai pada pre-post testnya. Setelah ditelisik tim mengetahui masih ada yang tidak dipahami oleh orang tersebut. Hal ini sejalan dengan penelitian Putri (2017) dalam Purnamasari (2020) bahwa salah satu faktor internal yang mempengaruhi tingkat pengetahuan seseorang adalah tingkat pendidikan, semakin tinggi tingkat pendidikan 
seseorang maka semakin tinggi pula pengetahuan (Purnamasari I and Raharyani A, 2020).

Perbedaan rata-rata antara sebelum dan sesudah intervensi penyuluhan dapat diketahui dengan lakukan uji statistik. Hasil dari uji $\mathrm{T}$ independent penyuluhan adabtasi kebiasaan baru pandemi covid-19 ini menunjukkan $p$-value sebesar 0.052 ( $p$ value $>0.05$ ) yang artinya bahwa tidak terdapat perbedaan rata-rata pengetahuan antara sebelum dan sesudah dilakukan penyuluhan. Edukasi sangat diperlukan untuk memperbaiki persepsi masyarakat yang masih kurang tepat. Menurut Olum dkk (2020) pendidikan professional berkelanjutan diperlukan untuk meningkatkan pengetahuan dan mengubah sikap negatif serta meningkatkan praktik pencegahan dan pengobatan (Olum et al., 2020).

Menurut teori Model PengetahuanSikap-Perilaku, pengetahuan merupakan faktor esensial yang dapat mempengaruhi perubahan perilaku, dan individu dapat memperoleh pengetahuan dan ketrampilan melalui proses belajar. Melihat masih adanya masyarakat yang memiliki pengetahuan yang kurang, dengan demikian pengetahuan masyarakat yang masih perlu diluruskan dan perilaku masyarakat yang masih negatif dapat diupayakan dengan kegiatan pembelajaran melalui edukasi oleh pihak-pihak yang berwenang. Dalam masyarakat, forum kesehatan desa atau sejenisnya dapat mengambil peran dalam upaya pelaksanaan kegiatan dimaksud (Liu et al., 2016).

\section{SIMPULAN DAN SARAN}

Berdasarkan hasil kegiatan pada hasil pre-post Test penyuluhan mengenai stop buang air besar sembarang dan pentingnya jamban sehat diketahui bahwa setelah diberikan penyuluhan pengetahuan responden meningkat. Berdasarkan hasil dari uji wilcoxon didapatkan hasil sebesar 0.038 ( $p$-value<0. 05) maka $\mathrm{Ho}$ ditolak dan $\mathrm{H} 1$ diterima yang artinya bahwa terdapat perbedaan rata-rata pengetahuan antara sebelum dan sesudah dilakukan penyuluhan.

Berdasarkan hasil kegiatan pada hasil pre-post Test penyuluhan mengenai pengelolaan sampah rumah tangga diketahui bahwa setelah diberikan penyuluhan pengetahuan responden meningkat. Berdasarkan hasil dari uji wilcoxon didapatkan hasil sebesar 0.024 ( $p$-value<0. 05) maka Ho ditolak dan $\mathrm{H} 1$ diterima yang artinya bahwa terdapat perbedaan rata-rata pengetahuan antara sebelum dan sesudah dilakukan penyuluhan.
Berdasarkan hasil kegiatan pada hasil pre-post Test penyuluhan mengenai adabtasi kebiasaan baru pandemi covid-19 diketahui bahwa setelah diberikan penyuluhan pengetahuan responden meningkat. Berdasarkan hasil dari uji $\mathrm{T}$ Independent didapatkan hasil sebesar 0.052 ( $p$-value>0.05) maka $\mathrm{Ho}$ diterima dan $\mathrm{H} 1$ ditolak yang artinya bahwa tidak terdapat perbedaan rata-rata pengetahuan antara sebelum dan sesudah dilakukan penyuluhan.

Saran kepada peserta kegiatan agar pengetahuan yang didapat dalam kegiatan pengabdian ini dapat diterapkan di kehidupan sehari-hari agar terhindar dari dampak-dampak yang muncul akibat buang air besar sembarangan, pengelolaan sampah rumah tangga yang tidak baik dan Covid-19 yang dibiarkan.

\section{UCAPAN TERIMAKASIH}

Ucapan terimakasih kami sampaikan kepada berbagai pihak, diantaranya kepada pihak kampus kami Program Studi Kesehatan Masyarakat Fakultas Kedokteran Universitas Lambung Mangkurat dan kepada seluruh masyarakat yang telah berkenan mengikuti rangkaian kegiatan penyuluhan dari kami sehingga berjalan dengan baik dan lancar

\section{DAFTAR RUJUKAN}

Febriani, W., Samino, \& Sari, N. (2016). Faktor Yang Mempengaruhi Perubahan Perilaku Stop Buang Air Besar Sembarangan (BABS). Jurnal Dunia Kesmas, 5(3), 121130. https://doi.org/10.33024/jdk.v5i3.467

Kementerian Kesehatan RI. (2020). Profil Kesehatan Indonesia Tahun 2019. Kementerian Kesehatan RI.

Liu, L., Liu, Y. P., Wang, J., An, L. W., \& Jiao, J. M. (2016). Use of a knowledge-attitudebehaviour education programme for Chinese adults undergoing maintenance haemodialysis: Randomized controlled trial. Journal of International Medical Research, 44(3), 557-568. https://doi.org/10.1177/03000605156049 80

Maghfiroh, S. A., Puji, H., \& Ariefin, M. (2018). Pengaruh Penyuluhan Tentang Sampah Terhadap Pengetahuan, Sikap dan Perilaku lbu Rumah Tangga (Anggota PKK) Dalam Mengelola Sampah Rumah Tangga Pada Permukiman Tradisional dan Permukiman Modern di Kelurahan Pudak Payung. Edu Geography, 6(2), 118-128.

Mukti, D., Raharjo, M., \& Dewanti, N. (2016). Hubungan Antara Penerapan Program Sanitasi Total Berbasis Masyarakat 
(Stbm) Dengan Kejadian Diare Di Wilayah Kerja Puskesmas Jatibogor Kabupaten Tegal. Jurnal Kesehatan Masyarakat Universitas Diponegoro, 4(3), 767-775.

Olum, R., Chekwech, G., Wekha, G., Nassozi, D. R., \& Bongomin, F. (2020). Coronavirus Disease-2019: Knowledge, Attitude, and Practices of Health Care Workers at Makerere University Teaching Hospitals, Uganda. Frontiers in Public Health, 8(April), 1-9. https://doi.org/10.3389/fpubh.2020.00181

Pratomo, S. (n.d.). Pengaruh Strategi Penyuluhan Dan Tingkat. 1(2), 110-128.

Purnamasari I and Raharyani A, E. (2020). Tingkat Pengetahuan Dan Perilaku Masyarakat Kabupaten Wonosobo Tentang Covid-19', Jurnal IImiah Kesehatan, I, pp. 33-43. Available at: https://ojs.unsiq.ac.id/index.php/jik/article/ view/1311/783. JurnallImiahKesehatan, Mei, 33-42. https://ojs.unsiq.ac.id/index.php/jik/article/ view/1311/783

Rahman, M. A. U. (2014). Pelestarian Rumah Lanting Berlandaskan Budaya Sungai Masyarakat Kota Banjarmasin. E-Journal Graduate Unpar, 1(2), 221-231. http://journal.unpar.ac.id/index.php/unpar graduate/article/view/1054

Ramadhanti, C. A., Adespin, D. A., \& Julianti, H. P. (2019). Perbandingan Penggunaan Metode Penyuluhan Dengan Dan Tanpa Media Leaflet Terhadap Pengetahuan Dan Sikap Ibu Tentang Tumbuh Kembang Balita. Diponegoro Medical Journal (Jurnal Kedokteran Diponegoro), 8(1), 99-120. 